\title{
The EXPERIENCES and PERCEPTIONS of
}

\section{nursing service managers regarding \\ TRANSFORMATION of bealth services in selected provincial academic bealth complexes}

\author{
R Buys \\ Master student \\ Nursing Department \\ RAU
}

$\&$

M Muller

D.Cur.

Professor of Nursing RAU

\section{Abstract}

Nursing service managers are challenged with enormous transformations within the new political dispensation in South Africa. The objective of the study was to explore and describe the experiences and perceptions of the nursing service managers regarding transformation of health services in selected Provincial Academic Health Complexes. A qualitative, exploratory, descriptive and phenomenological design was employed utilising focus group interviews and narratives as methods of data collection. After content analysis was performed, results were grouped into management of health service transformation and quality of patient care in relation to the levels of the organisation. The levels in the organisation are individual level, group level, departmental level and organisational level. Positive and negative experiences and perceptions were identified.

\section{Introduction}

As we enter the new millenium, we know that change is the only constant in the health services that will follow us into the twenty-first century. Since 1994, with the new political dispensation that took place in South Africa, many national, provincial and local policies and practices have changed resulting in a great necessity for the Government to transform the country. After finalisation and implementation of the transformational policies in 1997, real impact was felt within the health services' context. The approach of primary health care forms the underlying philosophy in restructuring the health care system. The aim is to reduce inequalities regarding access to health services, especially in the rural areas and deprived communities (ANC: The $\mathrm{Na}$ tional Health Plan, 1994). The transformation of health services in provinces, is thus part of a broader process in South Africa's transition and the whole motivation for transformation is to create a public health service that is more efficient and more rationally organised in terms of care, utilization of services and elimi- nation of overlapping. This gave rise to closure of certain institutions. The aim of transformation is to have more equitable health service, in terms of the distribution of staff and other resources between institutions that used to be on the opposite side of the apartheid line. A number of underutilized hospitals were placed with community health care facilities.

The transformation of health services in a selected province, with its new policies, especially those affecting attitudes and beliefs can be a difficult process, creating for many a period of uncertainty and role ambiguity. Nursing service managers are one of the keys to the transformation of health services because they manage large quantities of human, financial and technological resources. The transformation has been so major that the role responsibilities of the nursing service mangers have changed to such an extent, that they are now required to manage multi-cultural societies and personnel with different values, cultures and attitudes. As nursing service managers pioneered the transformation of health service delivery, it is essential for them to be skilled in scanning the environment, monitoring trends, forecasting direction of trends and assessing the responses to opportunities and threats. This knowledge and insights are valuable in planning transformational initiatives and creating visions of a new transformed system. Understanding the current health system provides a solid foundation for all successive planning and the skill levels of nursing service managers are thus critical to their effectiveness in the future. The researcher is concerned about the skills of the nursing service managers and how prepared they are for their new roles. Major changes causes disharmony within the individual system. The researcher was thus also concerned about the experiences and perceptions of the nursing service managers regarding transformation of health services in selected Provincial Academic Health Complexes, due 
to the fact that major changes usually cause disharmony within the individual systems. No research has been conducted to explore and describe the experiences and perceptions of the nursing service managers regarding transformation of health services in a selected province. Consequently nursing service managers find themselves making major decisions about transformation of health care delivery with little information about the effectiveness of alternative approaches. If experiences and perceptions of the nursing service managers regarding transformation of health services in selected Provincial Academic Health Complexes can be identified, ways to assist the nursing service managers in their role as transformation agents can be recommended, because the skills required differs substantially form those that were expected and rewarded in the past. The following research question became relevant: What are the experiences and perceptions of the nursing service managers regarding the current transformation of health services in selected Provincial Academic Health Complexes?

The objective of the study is to explore and describe the experiences and perceptions of the nursing service managers regarding transformation of health services in selected Provincial Academic Health Complexes.

\section{Terminology \\ Transformational management}

Transformational management is the process of change within selected Provincial Academic Health Complexes, which occurs at individual, group, departmental and organisational levels in relation to major restructuring, re-engineering, merging or conversion of services.

\section{Academic Health Complex}

It is a government hospital and refers to any academic, regional and community hospital which is involved in the process of transformational management in the region/province.

\section{Health service}

It refers to a public health service provided to individual patients, their families and communities in selected Academic Health Complexes.

\section{Experiences}

Experiences refer to the reality, which the nursing service managers find themselves in during the transformation of health services in selected Provincial Academic Health Complexes.

\section{Perceptions}

Perceptions are the knowledge, beliefs and opinions expressed by the nursing service managers regarding transformation of health services in selected Provincial Academic Health Complexes.

\section{Nursing service managers}

Nursing service managers refer to nurses/midwives who are registered with the South African Nursing Council, who are appointed in posts as Deputy Directors, Assistant Directors and Chief Professional Nurses in selected Provincial Academic Health Complexes.

\section{Research Strategy and Metbod}

A qualitative, exploratory, descriptive and contextual design was utilized to conduct this research (Mouton \& Marais, 1992:45, 175; Mouton, 1996:103-109). A phenomenological method using narratives and focus group interviews (Holloway \& Wheeler, 1996:59; Krueger, 1994:16-20) was conducted to obtain data that would facilitate an understanding of how the nursing service managers experience and perceive the transformation of health services in selected Provincial Academic Health Complexes. Themes were identified and recommendations will be made to assist the nursing service managers in their role as transformational agents.

The population of the study consisted of all public hospitals in the province/region where transformation is taking place. Four hospitals were purposively selected after fulfilling the criteria set for this research. The criteria are: being in the process of undergoing major restructuring, re-engineering, redesign changes; in the process of merging/amalgamating or conversion. Accessibility was also a major criterion and hospitals had to give consent to conduct the research. Two of the hospitals were in the process of merging and the other two had major restructuring changes. Thirty-four nursing service managers were purposively selected after fulfilling the criterion of being leaders in their professions, involved in the development of policy in their institutions and are registered with the South African Nursing Council. Table one reflects participants, i.e. nursing service managers by hospital and seniority.

Focus group interviews and written narratives were utilized to collect data on the experiences and perceptions of nursing service managers regarding transformation of health services in selected Provincial Academic Health Complexes. Nursing service managers in these Provincial Academic Health Complexes participated in the focus group interviews. An independent moderator, to enhance trustworthiness of the study, conducted the focus group interviews. One main theme was standardised after realising that all groups from the hospitals were homogeneous, and would have similar perspectives and concerns regarding transformation of health services. The main theme was "The experiences and perceptions of nursing service managers regarding transformation of health services in the province/region". A course of non-directiveness was followed and each participant was given an opportunity to express himself/herself openly and freely. The moderator facilitated the interviews by creating an open, non-threatening atmosphere. The interviews were audiotaped and transcribed verbatim by the researcher. The researcher made fieldnotes (observational, theoretical and experiential) directly after the interviews as a triangulation method (Wilson, 1989:436-438). Three nursing service managers, who gave consent to write narratives, used blank sheets to write on, on which the following central instruction appeared: "Please describe your experiences and perceptions regarding the transformation of health services in the province/ region".

Tesch's method (in Cresswell, 1994:154155) of content analysis was adopted as a basis for data analysis. Data was analysed independently by two researches, followed by a consensus discussion. After the analysis of four focus groups' transcribed interviews and three written narratives, theoretical sampling saturation was achieved as evidenced in the repeating themes.

Lincoln and Guba's (1985:218-331) four strategies of trustworthiness were followed to ensure the establishment and maintenance of trustworthiness. The researcher had prolonged exposure to collected data, four focus group interviews were conducted, fieldnotes were taken as part of data collection and the researcher had two year's involvement with the study. Utilising multiple sources of data ensured triangulation and data control was executed by two independent researchers - an expert study leader in nursing dynamics, as well as a costudy leader. A thick description of data by the researcher provided required information to other researchers, should they want to prove transferability. The researcher bracketed herself and col- 
focus group interviews, in relation to management and the quality of patient care.

Informed written consent was obtained from the Provincial Health Department, all four hospitals' superintendents and all the participants involved. Measures to ensure anonymity, confidentiality and privacy were given priority. Only the data pertaining to the research topic was collected, and all audiotapes were destroyed after completion of the study. The results of the study will be available to the nursing service manager who participated in the study (South African Nursing Association, 1991:5).

\section{Results and Discussion}

Two major themes were identified from the data, namely the management function and the quality of patient care. The themes and categories that were identified through analysis of transcribed focus group interviews and written narratives, confirmed that transformation of health services occurs at all levels of the organisation. The levels are individual level, group level, departmental level and organisational level. Individual level refers to the effect of transformation of health services on nursing service managers as individuals. Group level refers to the effect of transformation of health services on nursing service managers as a group, collectively and their interaction and inter-relationship with one another Departmental level refers to the effect of transformation of health services on different sections of the organisation and organisational level refers to the effect of transformation of health services on the organisation as a whole.

All these levels are interacting and integrating. It became evident that the nursing service mangers experienced and perceived transformation of health services as occurring at all levels of the organisation, and transformation has a positive and/or negative impact on management functions and the quality of patient care. The results are discussed, based on the two major themes, in relation to all the levels of the organisation and the positive and/or negative experiences and perceptions of the nursing service managers regarding transformation of health services. For the purpose of clarification and reference, the results are presented in table two, which display an overview of the experiences and perceptions of nursing service managers regarding transformation of health services in selected Provincial Academic Health Complexes.

The main themes, categories and sub categories are discussed in greater detail, which are supported by quotes from the written narratives and transcribed

\section{Management}

Nursing service managers identified various categories of their experiences and perceptions regarding the changes and effects of the transformation of health services on their management function at all levels of the organisation. Positive and negative experiences and perceptions were identified and discussed with supporting quotations from the participants written narratives and focus group interviews (see table three). Different levels of transformation management emerged: individual and group level, as well as departmental and organizational levels.

\section{Individual and group levels}

It became clear from the results that negative feelings like anger, fear, uncertainty, powerlessness and low morale were common among the nursing service managers and dominated their emotions. Nursing service managers expressed that they have these negative feelings in response to poor communication, increased workload, poor salaries, lack of recognition, inadequate resources and lack of participation in decision making. The participants indicated that they were continuously dissatisfied and unhappy and their thoughts are summarized in the following statements: "... there is a shortage of staff the whole situation makes me angry, bloody angry..." Another participant stated: "... with all these rumours we feel very uncertain about ourjobs, there's also lots of fear of loosing our jobs ... the whole situation is hurting, hurting painfully ..." (Tears running down her cheeks).

Lack of effective communication was described by most participants as a major stumbling block of transformational management and the information regarding health services was perceived to be insufficient. The transformation was perceived by the participants as being characterised by rumours and these rumours elicit uncertainty, fear and anxiety which have a negative impact on transformational management. During all four focus groups, the participants said that communication was from the top down, i.e. there is no two-way communication. In all the narratives, poor communication was not mentioned. Poor communication was confirmed by the following quotations from transcribed focus group interviews: "We don't get clear information about the short-term and long-term goals ... and information about changes is given to us when decisions are already made ... there's no two-way communication". "I feel lots of information is being withheld..." "When it comes to information, we get very little feedback from the authorities (Provincial Health Department)..."

The nursing service managers also perceived inadequate recognition by the Provincial Health Department. The participants mentioned their dissatisfaction with the poor salaries they receive. Poor salaries and lack of recognition were seen as contributing to the low morale which have a negative impact on their management function. This was clearly described by one participant: "...the salaries are so pathetic, nurses receive no recognition at all..." Another participant said that they were not adequately financially remunerated for their efforts, considering the many years of service. The following statement evidenced this: "... after thirty years of service for the government, we still earn a pathetic salary..." Several participants also made reference to the ineffective performance evaluation system (PPMS) as indicated by the following statements: "... hmm ... like the PPMS ... it is a system that is very complicated and is not working..." "... the PPM is a big problem, it's not effective at all..."

Workload issues described were increased numbers of patients and shortage of personnel. A number of nursing service managers felt that the moratorium on filling of vacant nursing posts, the severance packages, the resignation of highly skilled nurses and the free health services contributed to the increased workload and this had a negative effect on their management function. Increased workload was a serious concern of the participants, and they viewed it to be the main factor that retards transformational management. The following statements supports this concern: “... the nurses are overworked and generally the wards are full ... also the number of patients increased tremendously ... we cannot handle them all in good time... I'm not coping with what I'm ... there's too much demand on me ... I feel I'm doing the work of at least two managers .. the workload have increased so much that I personally feel stressed and at times very angry about the transformation..."

The absence of consultation with the nursing service managers as well as the lack of involvement of participants in transformational issues and decisions was raised by most nursing service managers. The participants felt that the Provincial Health Department did not involve them in decision making regarding 
changes. The participants expressed their dissatisfaction with the behaviour of the Provincial Health Department and said this Health Department is very autocratic. This concern was supported and confirmed by the following quotations: "... too many things are actually forced unto us. We are not involved in most of the planning ... there is no negotiation and no democracy ... no participation and no involvement by nurses. The whole transformation is from top down..."

Some participants highlighted lack of professional development as another important factor that retards transformational management. The participants felt that the Provincial Health Department was not fully committed to professional development of the nursing service managers. The participants indicated that it was difficult to obtain bursaries and study leave to develop themselves professionally. They mentioned that the financial remuneration that they receive after developing themselves professionally was not worth the effort, although it is necessary for them to acquire new skills and knowledge to cope with the changes. The following statements supports this concern: "... when it comes to professional development, / feel the ... Health Department is not fully committed ... I cannot understand how the government expects us to display the necessary competence for change management if we are not given bursaries and opportunities to do management courses ... even if you develop yourself, you get no increase of salary for your qualifications..."

Despite the negative effects of the transformation of health services on the individuals and groups, some participants described the transformation as having resulted in a positive effect, because it contributed to knowledge of cultural diversity and better race relations. The participants felt that they now understand each other's behaviours better, and different races are learning about each other's lifestyles. This was supported by the following statements: “... to me, transformation resulted in different people knowing one another culturally, socially and understanding each other's values better... / also think you learn how to deal with diverse problems better you are on your toes all the time..." Another participant wrote: "We now understand each other's behaviours better

I feel we are empowered in this way".

\section{Departmental and organisational level}

Resource issues described by the majority of the participants were shortage of nursing personnel and inadequate material resources having a negative impact on the transformation process. The participants mentioned that without nurses and necessary structures, management of the departments was extremely difficult. This was verified by the following quotations from the transcribed focus group interviews and written narratives: "... without nurses and without structures it is extremely difficult for us managers ... there is a shortage of staff and nurses perceive the situation negatively ... it causes many problems ... the nursing staff is getting lesser and lesser some nurses go many months without annual leave because of shortage..."

Recruitment and promotion procedures based on non-discriminatory criteria of competency and experience were mentioned by nursing service manager as a positive "thing" the transformation brought about. The participants' views regarding non-discriminatory policies, were as follows: "... now there is no more segregation, all races benefit equally from health services ... it is clear that most institutions were predominantly white, have people of colour in great numbers as health workers as well as in managerial positions ..."

The results of this study show that the nursing service managers at all four hospitals were very unhappy about the way the transformation of health services was implemented. Most nursing service managers experienced negative feelings of anger, frustration, fear, uncertainty, powerlessness, low morale and hurt associated with the transformation of health services. Poor communication, increased workload, poor salaries, lack of recognition, inadequate resources and lack of participation in decision-making were perceived as contributing to these negative feelings and have a negative impact on their functioning as transformational managers in selected Provincial Academic Health Complexes.

Insufficient information by the Provincial Health Department and a top-down information approach, were perceived as retarding transformational management. The nursing service managers wanted specific information about goals, roles, timeframes and anticipated problems regarding the transformation. The nursing service managers experience and perceive poor salaries and lack of recognition as factors that have a negative impact on their functioning as transformational managers in selected Provincial Academic Health Complexes.

The nursing service managers experienced a lack of professional development since bursaries and study leave are difficult to obtain. Lack of professional development hinders effective management because they need to acquire the necessary competencies for effective change management.

Increased workload due to shortage of staff and increased numbers of patients were experienced by the majority of nursing service managers. Increased workload was seen as a serious concern and it was said to be the main issue, which hinders transformational management in selected Provincial Academic Health Complexes. The nursing service managers experienced and perceived inadequate resources as a contributing factor to ineffective management of the institutions. The moratorium placed on staff employment and shortage of equipment were perceived by the nursing service managers as having a negative affect on their management function.

Despite the negative experiences and perceptions, some nursing service managers felt empowered by the transformation of health services in terms of cultural diversity and better race relations. The nursing service managers also felt that the non-discriminatory recruitment and promotion policies resulted in all races equally benefiting from the health services.

\section{Quality of Patient Care}

Nursing service managers identified various categories of their experiences and perceptions regarding the changes and the effect of transformation of health services on the quality of patient care. Positive and negative experiences were identified and are discussed with supporting quotations from the participants' written narratives and focus group interviews (see table four).

\section{Individual, group, department and organisation}

The majority of the participants said that inadequate supervision of human and material resources make it difficult for them to adequately and appropriately respond to the health needs according to the demographic pattern of the general population. The participants believed that the patients were not receiving quality care and they mentioned that standards of patient care are dropping because of the shortage of personnel and other resources. One participant said: "... the transformation resulted in the cut of the budget, which now means that maintenance and acquiring of machinery is being compromised ... I think 
it is very unfair ... unfair to the patients because they are the recipients of care " "... patients sit for hours and hours waiting to be seen and for beds..." Another participant said: "... the general mortality rate has increased ... many times due to longer waiting periods, limited facilities and shortage of doctors and nurses ..."

The participants said that lack of adequate resources was due to increased workload, poor salaries, negative feelings and lack of professional development.

It was mentioned that free health services have a positive and negative effect on the quality of patient care. The participants felt that there is no adequate provision of human and material resources and this makes patient care delivery difficult. The negative impact of free health services was verbalized by the participants as follows: "... no adequate provision of human and material resources was made enable staff to adequately and appropriate/y respond to the health needs according to the demographic pattern of the general population ... health facilities have to face an influx of patients with no staff and no medication in most clinics ... hospitals remain constantly overcrowded and thus become ineffective and inefficient..." The participants also mentioned that free health services was "a good thing" especially for the disadvantaged communities. This was verified by the following quotations derived from the transcribed interviews and written narrative: “... the transformation of health services is a good thing, especially for the disadvantaged communities ... primary health care is equitable, accessible and available to all, even in the remote areas..."

Some participants said that the elimination of racial discrimination policies was having a positive impact on patient care. The participants stated that: "... with this transformation there is no longer segregation, all races benefit equally from the health services..."

The nursing service managers in these Provincial Academic Health Complexes perceived inadequate material and human resources as contributing factors to the deteriorating quality of patient care Shortages of personnel increased the workload, which have a negative effect on the quality of patient care. Inadequate resources was intensely experienced by the nursing service managers Free health services and primary health care was perceived and experienced by the nursing service managers as beneficiary to the disadvantaged and poor communities and free health services and primary health care services contrib- uted to hospitals being compromised. The nursing service managers perceived the elimination of discriminatory policies as an equal benefit to all races.

\section{Conclusions}

There were both positive and negative experiences by the nursing service managers. The following concluding statements are made:

- Effective two-way communication is the key to effective transformation of health services. There is more power to be gained by sharing information than when withholding it.

- Professional development enhances the efficacy of health service transformational management, thus continuous learning is necessary for the health services' transformational management.

- The negative impact of transformation results in negative feelings, which tend to perpetuate themselves and affects the way people act

- Increased workload and shortage of staff are interrelated and retards transformation of health services.

- Participation and communication are interrelated and are vital to transformation of health services.

- Poor salaries and lack of recognition contributes to low morale and negative feelings.

- Lack of material and human resources retards the transformational management and the quality of patient care.

\section{Recommendations}

It is recommended that the results of this study should be used as part of a conceptual framework for transformational management in the nursing service. Standards on transformational management should be formulated which can be used to evaluate the quality of trans. formational management.

\section{Concluding Remarks}

Nursing service managers in selected Provincial Academic Health Complexes are challenged with transformational management. The focus of this research was to explore and describe the experiences and perceptions of the nursing service managers regarding transformation of health services in these selected Provincial Academic Health Complexes. The results are grouped according to the management function and quality of patient care in relation to individual, group, departmental and organisational levels with the negative and/or positive effects. The results will be used in conjunction with a literature control to develop a conceptual framework and standards for transformational management will be formulated. The literature control is not included in this article, but will form part of a follow-up article as part of the conceptual framework for the standards.

\section{Acknowledgements}

We hereby thank the nursing service managers for their input and time amidst the pressures of transformation. 
Table 1: Participants i.e. Nursing Service Managers by Hospital and Seniority

\begin{tabular}{|l|l|l|l|l|l|}
\hline & Hospital A & Hospital B & Hospital C & Hospital D & Total \\
\hline Deputy Director & 1 & & & 1 & 2 \\
\hline Assistant Director & 4 & & 2 & 2 & 8 \\
\hline Chief Professional & 5 & 7 & 8 & 4 & 24 \\
\hline Nurse & & & & & \\
\hline Totals & 10 & 7 & 10 & 7 & 34 \\
\hline
\end{tabular}

Table 2: Distribution Of Main Themes, Levels, Categories And Subcategories

\begin{tabular}{|c|c|c|c|}
\hline MAIN THEME & LEVEL & CATEGORY & SUBCATEGORY \\
\hline$\frac{E}{\frac{1}{4}}$ & $\begin{array}{l}\text { Individual } \\
\& \\
\text { Group } \\
\text { Department } \\
\text { \& } \\
\text { Organisation }\end{array}$ & $\begin{array}{l}\longrightarrow \\
\text { Positive } \longrightarrow \\
\text { Pogative } \longrightarrow\end{array}$ & $\begin{array}{l}\text { ive feelings } \\
\text { communication } \\
\text { salary } \\
\text { of recognition } \\
\text { of participation } \\
\text { sed workload } \\
\text { of professional } \\
\text { opment } \\
\text { werment } \\
\text { of resources } \\
\text { iscriminatory } \\
\text { is }\end{array}$ \\
\hline 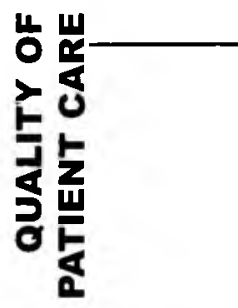 & $\begin{array}{l}\text { Individual } \\
\& \\
\text { Group } \\
\& \\
\text { Department } \\
\& \\
\text { Organisation }\end{array}$ & Negative & $\begin{array}{l}\text { fesources } \\
\text { lealth service \& PHC } \\
\text { iscriminatory policies } \\
\text { lealth service \& PHC }\end{array}$ \\
\hline
\end{tabular}

Table 3: Ddistribution of positive and negative experiences and perceptions of nursing service managers regarding transformation of health services' effect on management functions

\begin{tabular}{|lll|}
\hline & FOCUS GROUP & NARRATIVE \\
\hline SUBCATEGORIES & $\mathrm{N}$ & $\mathrm{N}$ \\
\hline Negative feelings & 4 & 2 \\
Poor communication & 4 & \\
Poor salary and lack of recognition & 4 & 2 \\
Increased workload & 4 & 3 \\
Lack of participation & 4 & \\
Lack of professional development & 2 & 1 \\
Empowerment & 2 & \\
\hline SUBCATEGORIES & $\mathrm{N}$ & $\mathrm{N}$ \\
\hline Lack of resources & 4 & 3 \\
Non-discriminatory policies & 2 & 1 \\
\hline
\end{tabular}


Table 4: Distribution of positive and negative experiences and perceptions of nursing service managers regarding transformation of health services and its effect on patient care quality

\begin{tabular}{|lll|}
\hline & FOCUS GROUP & NARRATIVE \\
\hline SUBCATEGORIES & $\mathrm{N}$ & $\mathrm{N}$ \\
\hline Lack of resources & 4 & 3 \\
Free health services & & \\
PHC and negative impact & 4 & 3 \\
Non-discriminatory policies & 3 & \\
Free health service and PHC - positive impact & 4 & 3 \\
\hline
\end{tabular}

References

AFRICAN NATIONAL CONGRESS. 1994. A national health plan for South Africa. Lesotho: Bahr Mapping and Printing.

CRESSWELL, J.W. 1994. Research design: qualitative and quantitative approaches. New Delhi: Sage Publications.

LINCOLN, Y .S., \& GUBA, E.C. 1985. Naturalistic inquiry. London: Sage.

KRUEGER, R. A. 1994. Focus groups, a practical guide for applied research. London: Sage.

MOUTON, J. 1996. Understanding social research. Pretoria: Van Schaik.

MOUTON, J. \& MARAIS, H.C. 1992. Basiese begrippe: metodologie van Geesteswetenskappe. Pretoria: Raad vir Geesteswetenskaplike Navorsing.

SOUTH AFRICAN NURSING ASSOCIATION. 1991. Position paper: ethical standards for nurse researchers. Pretoria: SANA.

HOLLOWAY, I., \& WHEELER, S. 1996. Qualitative research for nurses. London: Blackwell Science.

WILSON, H.S. 1989. Research in nursing. California: Addison-Wesley. 